\title{
Implementasi Metode Multi Attribute Utility Theory (MAUT) pada Aplikasi Pemilihan Staf Berprestasi Dinas Pangan Pertanian dan Perikanan Kota Pontianak
}

\author{
Ridho Kariman $^{\# 1}$, Heri Priyanto ${ }^{\# 2}$, Helen Sastypratiwi ${ }^{\# 3}$

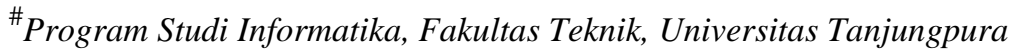 \\ Jl. Prof. Dr. Hadari Nawawi, Pontianak 78124 \\ ${ }^{1}$ ridhokarimanlegmail.com \\ ${ }^{2}$ heripriyanto.stmtegmail.com \\ ${ }^{3}$ helensastypratiwieinformatika.untan.ac.id
}

\begin{abstract}
Abstrak
Perkembangan teknologi pada saat ini sangat berguna bagi manusia dan memudahkan kita untuk mengatasi berbagai masalah yang membutuhkan waktu lebih efisien, salah satunya yaitu pengambilan keputusan dalam pemilihan staf berprestasi di Dinas Pangan Pertanian dan Perikanan Kota Pontianak, karena staf yang memiliki kinerja yang baik merupakan hal penting dalam memajukan dan mempertahankan mutu dinas ini. Saat ini, Dinas Pangan Pertanian dan Perikanan dalam mendapatkan rekomendasi staf berprestasi masih dengan cara musyawarah untuk memilih staf berprestasi sehingga memakan waktu yang cukup lama karena banyaknya jumlah staf yang harus dinilai dan diperlukannya keakuratan dalam pemilihan staf berprestasi, serta musyawarah juga sering melibatkan penilaian secara subjektif. Oleh karena itu, dibangunlah sebuah aplikasi untuk pemilihan staf berprestasi pada Dinas Pangan Pertanian dan Perikanan Kota Pontianak. Aplikasi ini dibangun berbasis web dengan menggunakan bahasa pemrograman PHP dan MySQL sebagai basis data. Metode pengambilan keputusan yang digunakan yaitu metode Multi Attribute Utility Theory (MAUT), metode ini digunakan untuk menentukan nilai bobot dari setiap kriteria, yang kemudian dilakukan proses pengurutan skor akhir dari tertinggi ke terendah (perangkingan) untuk menentukan rekomendasi alternatif terbaik hingga alternatif terburuk. Pengujian yang dilakukan pada penelitian ini yaitu pengujian akurasi dengan membandingkan skor akhir dari perhitungan menggunakan cara manual dan perhitungan yang dilakukan oleh aplikasi yang hasilnya hampir sama. Hasil pengujian menunjukkan bahwa aplikasi dapat berjalan dengan baik sesuai dengan fungsinya.

Kata kunci: Pemilihan Staf Berprestasi, Multi Attribute Utility Theory (MAUT), Dinas Pangan Pertanian dan Perikanan Kota Pontianak, Sistem Pendukung Keputusan, Website

\section{Implementation Method of Multi Attribute Utility Theory (MAUT) on the Application Selection Achievement staff of Food Agriculture and Fisheries Department of the city of Pontianak}

\begin{abstract}
The development of technology at this time is beneficial for humans and makes it easy for us to overcome various problems that require more efficient time, one of which is making decisions in the selection of outstanding staff in the Department of Agriculture and Fisheries of Pontianak, because staff who have excellent performance are essential in promoting and maintaining the quality of this service. At present, the Department of Agriculture and Fisheries Food in obtaining high-performance staff recommendations still deliberates to select high-performing staff. Hence, it takes a long time because of the large number of staff that must be assessed, and the accuracy required in the selection of high-achieving staff, and deliberations also often involve subjective evaluations. Therefore, an application was built for the variety of outstanding teams at the Pontianak City Agriculture and Fisheries Food Service. This application is made based on the web using the programming languages PHP and MySQL as a database. The decision-making method used is the Multi-Attribute Utility Theory (MAUT) method, this method is used to determine the weighting value of each criterion, which then processes the final score from highest to lowest (ranking) to determine the best alternative recommendations to the worst alternatives. Tests conducted in this study are testing accuracy by comparing the final score of calculations using the manual method
\end{abstract}


and calculations performed by applications whose results are almost the same. The test results show that the application can run well following its function.

Keywords: Selection of Achievement Staff, Multi-Attribute Utility Theory (MAUT), Pontianak City Agriculture and Fisheries Food Service, Decision Support System, Website

\section{Pendahuluan}

Berdasarkan Peraturan Daerah Nomor 07 tahun 2016 tentang Pembentukan dan Susunan Perangkat Daerah, Pemerintah Kota Pontianak menggabungkan dua institusi yaitu Dinas Pertanian, Perikanan dan Kehutanan Kota Pontianak dengan Kantor Ketahanan Pangan dan Penyuluhan Kota Pontianak menjadi satu institusi yaitu Dinas Pangan Pertanian dan Perikanan Kota Pontianak [1]. Sebagai institusi pemerintahan yang harus mempertahankan kredibilitasnya, maka dinas harus memiliki staf yang berkualitas dan professional dalam bidangnya agar selalu memberikan kinerja dan pelayanan yang terbaik bagi dinas itu sendiri dan Negara.

Staf Dinas Pangan Pertanian dan Perikanan mempunyai tugas pokok untuk melaksanakan tugas umum pemerintahan dan tugas pembangunan di daerah Kota Pontianak dalam bidang pangan, pertanian dan perikanan dibawah pengawasan langsung oleh walikota Pontianak [1]. Dalam lingkungan organisasi pemerintahan, seorang staf dituntut untuk bekerja sebagai abdi negara dan abdi masyarakat. Dari pemahaman ini diharapkan bahwa seorang staf haruslah memiliki kinerja yang baik, artinya mendapat kepercayaan dari publik atau masyarakat yang dilayani selain itu juga harus memiliki keterampilan yang dibutuhkan oleh masyarakat, serta mempunyai komitmen moral/etis dan bertanggungjawab penuh atas pekerjaannya kepada publik (public accountability). Kinerja yang baik dari seorang staf, dapat memberikan pertimbangan bagi kepala bidang sumber daya manusia (SDM) untuk menentukan staf berprestasi yang akan direkomendasikan ke kepala dinas agar tetap bekerja di dinas tersebut.

Saat ini, Dinas Pangan Pertanian dan Perikanan Kota Pontianak dalam mendapatkan rekomendasi dan memilih staf berprestasi masih menggunakan cara manual yaitu dengan musyawarah untuk memilih staf yang berkualitas. Bentuk musyawarah yang dilakukan yaitu membahas tentang kinerja staf non-ASN yang bekerja di dinas tersebut mengenai kedisplinan, pelaksanaan tugas, dan prakarsa. Musyawarah ini tentu dapat memakan waktu yang cukup lama dikarenakan banyaknya jumlah staf yang harus dinilai serta perlu keakuratan dalam pemilihan staf berprestasi. Musyawarah juga sering melibatkan penilaian secara subjektif.

Berdasarkan penjelasan yang telah dipaparkan di atas, maka perlu dilakukan pengembangan aplikasi pemilihan staf berprestasi yang dapat memberikan kemudahan dalam hal rekomendasi staf berprestasi dengan metode Multi Attribute Utility Theory (MAUT) dalam menentukan atau memilih staf berprestasi agar terciptanya SDM yang berkualitas dan berdedikasi tinggi.

\section{URAIAN PENELITIAN}

\section{A. Kinerja}

Kinerja adalah suatu hasil kerja yang dicapai seseorang dalam melakukan tugas-tugas yang dibebankan kepadanya yang didasarkan pada kecakapan, pengalaman, dan kesungguhan serta ketepatan waktu. Kinerja karyawan dipengaruhi oleh tiga faktor yakni kemampuan dan minat seorang pekerja, kemampuan dan penerimaan atas penjelasan delegasi tugas dan peran, serta tingkat motivasi seorang pekerja [2]. Fungsi pekerjaan atau kegiatan yang dimaksudkan disini adalah pelaksanaan hasil pekerjaan atau kegiatan seseorang atau kelompok yang menjadi wewenang dan tanggung jawabnya dalam suatu organisasi [3].

\section{B. Penilaian Kinerja}

Penilaian kinerja terdapat dua syarat utama yang dibutukan guna menjalankan penilaian kinerja yang baik, yakni: 1). Adanya ciri kinerja yang dapat di ukur secara objektif dalam proses evaluasi 2). Dari sudut pandang penggunaan kinerja itu sendir. Penilaian kinerja berperan sebagai pengembalian tentang berbagai aspek misalnya kemampuan, keterampilan, kelemahan dan kualitas yang pada giliran untuk manfaat tentukan tujuan karirnya. Sedangkan bagi instansi, hasil penilaian kinerja tentunya penting dalam kaitannya dengan megambil keputusan tentang beberapa aspek diantaranya identifikasi kebutuhan program pendidikan dan diklat, perekruitmen, seleksi, program perkenalan, penempatan, mutasi, balas jasa, serta berbagai hal lain dalam proses (SDM) [4] .

\section{Aplikasi}

Aplikasi adalah program komputer yang dibuat untuk membantu manusia dalam mengerjakan tugas-tugas tertentu. Artinya penerapan dari rancang sistem untuk mengolah data yang menggunakan aturan atau ketentuan bahasa pemrograman tertentu [5].

Secara istilah pengertian aplikasi adalah suatu program yang siap untuk digunakan yang dibuat untuk melaksanankan suatu fungsi bagi pengguna jasa aplikasi serta penggunaan aplikasi lain yang dapat digunakan oleh suatu sasaran yang akan dituju. Menurut kamus komputer eksekutif, aplikasi mempunyai arti yaitu pemecahan masalah yang menggunakan salah satu tehnik pemrosesan data aplikasi yang biasanya berpacu pada sebuah komputasi yang diinginkan atau diharapkan maupun pemrosesan data yang di harapkan [6].

Aplikasi merupakan penerapan, menyimpan sesuatu hal, data, permasalahan, pekerjaan kedalam suatu sarana atau media yang dapat digunakan untuk menerapkan atau mengmplementasikan hal atau permasalahan yang ada sehingga berubah menjadi suatu bentuk yang baru tanpa menghilangkan nilai-nilai dasar dari hal data, permasalahan, dan pekerjaan itu sendiri [7].

\section{Sistem Pendukung Keputusan}

Sistem pendukung keputusan bertujuan untuk menyediakan informasi membimbing, memberikan prediksi serta mengarahkan kepada pengguna informasi agar dapat melakukan pengambilan keputusan dengan lebih baik. Sistem pendukung keputusan merupakan implementasi teori-teori pengambilan keputusan yang telah 
diperkenalkan oleh ilmu-ilmu seperti operation research dan management science, hanya bedanya adalah bahwa jika dahulu untuk mencari penyelesaian masalah yang dihadapi harus dilakukan perhitungan iterasi secara manual (biasanya untuk mencari nilai minimum, maksimum, atau optimum), saat ini komputer PC telah menawarkan kemampuannya untuk menyelesaikan persoalan yang sama dalam waktu relatif singkat [8].

\section{E. MAUT}

Metode Multi Attribute Utility Theory (MAUT) merupakan metode yang fundamental selain metode MFEP (Multi Factor Evaluation process). Metode ini terlihat memiliki proses penyelesaian yang merupakan penggabungan metode Analithical Hierarchy Process (AHP) suatu metode pengambilan keputusan dengan melakukan perbandingan berpasangan antara kriteria pilihan dan juga perbandingan berpasangan antara pilihan yang ada, dan metode Simple Additive Weigthing (SAW) yaitu teknik perangkingan atau menentukan rating pada setiap atribut yang sebelumnya harus sudah melalui proses pengecekkan konsistensi kriteria normalisasi [9]. Dalam metode Multi Attribute Utility Theory (MAUT) digunakan untuk merubah dari beberapa kepentingan kedalam nilai numerik dengan skala $0-1$ dengan 0 mewakili pilihan terburuk dan 1 terbaik. Hal ini memungkinkan perbandingan langsung beragam ukuran. Hasil akhirnya adalah urutan peringkat dari evaluasi yang menggambarkan pilihan dari para pembuat keputusan [10].

\section{F. Prosedur MAUT}

1. Mendefinisikan terlebih dahulu kriteria-kriteria yang akan dijadikan sebagai tolak ukur penyelesaian masalah dan menentukan tingkat kepentingan setiap kriteria.

2. Menghitung nilai matriks perbandingan dari masing-masing kriteria berdasarkan table nilai kepentingan (Tabel I).

TABEL I

SKALA SAATY

\begin{tabular}{|c|c|}
\hline $\begin{array}{c}\text { Tingkat } \\
\text { Kepentingan }\end{array}$ & Definisi \\
\hline 1 & Kedua elemen sangat penting \\
\hline 3 & $\begin{array}{l}\text { Elemen yang satu sedikit lebih penting } \\
\text { dibanding elemen yang lain }\end{array}$ \\
\hline 5 & $\begin{array}{l}\text { Elemen yang satu esensial atau sangat } \\
\text { penting dibanding elemen yang lainnya }\end{array}$ \\
\hline 7 & $\begin{array}{l}\text { Elemen yang satu benar-benar lebih penting } \\
\text { dari yang lain }\end{array}$ \\
\hline 9 & Elemen yang satu mutlak lebih penting \\
\hline $2,4,6,8$ & Nilai tengah diantara dua penilaian berurutan \\
\hline Kebalikan & $\begin{array}{l}\text { Jika aktivitas I mendapat satu angka } \\
\text { dibandingkan dengan aktivitas } \mathrm{j} \text {, maka } \mathrm{j} \\
\text { memiliki nilai kebalikannya dibandingkan } \\
\text { dengan } \mathrm{i}\end{array}$ \\
\hline
\end{tabular}

3. Menghitung nilai lamda max.

$\lambda \max =\frac{\sum \lambda}{\mathrm{n}}$

Keterangan :

$\sum=$ Jumlah Matriks Baris,

$\mathrm{n}=$ Jumlah kriteria
4. Menghitung nilai Consistency indeks (CI).

$C I=\frac{\lambda \max -n}{\mathrm{n}-1}$

Keterangan :

$\mathrm{CI}=$ Indeks Konsistensi (Consistency Index),

$\lambda \max =$ Nilai eigen terbesar dari matrik berordo $n$

5. Menghitung konsistensi (CR) dari nilai perbandingan antar kriteria.

$C R=\frac{C I}{\mathrm{RC}}$

Keterangan :

$\mathrm{CR}=$ Consistency Ratio

$\mathrm{CI}=$ Consistency Index

$\mathrm{RC}=$ Random Consistency

\begin{tabular}{cccccccccccc}
\hline$n$ & 1 & 2 & 3 & 4 & 5 & 6 & 7 & 8 & 9 & 10 & 11 \\
\hline $\operatorname{RC}$ & 0,00 & 0,00 & 0,58 & 0,90 & 1,12 & 1,24 & 1,32 & 1,41 & 1,45 & 1,49 & 1,51 \\
\hline \multicolumn{1}{r}{} & Gambar. 1 Skala nilai RC
\end{tabular}

Dimana RC adalah nilai yang berasal dari tabel random seperti pada Gambar 1.

a. Jika $\mathrm{CR}<0,1$ maka nilai perbandingan berpasangan pada matriks kriteria yang diberikan konsisten.

b. Jika $\mathrm{CR}>0,1$ maka nilai perbandingan berpasangan pada matriks kriteria yang diberikan tidak konsisten.

c. Sehingga jika tidak konsisten, maka pengisian nilai-nilai pada matriks berpasangan pada unsur kriteria maupun alternatif harus diulang.

6. Menghitung nilai bobot preferensi (Vi).

$V i=\sum_{j=1}^{n} \lambda \max * r i$

Keterangan :

$\mathrm{Vi}=$ Bobot Preferensi (Skor)

$\sum_{j=1}^{n} \lambda \max * r i=$ Bobot Kriteria

ri $=$ Nilai Alternatif Setiap Kriteria

7. Perangkingan

\section{G. Unified Modelling Language (UML)}

Unified Modeling Language (UML) adalah salah satu standar bahasa yang banyak digunakan di dunia industri untuk mendifinisikan requirement, membuat analisis \& desain, serta mengambarkan arsitektur dalam pemograman berbasis objek. UML hanya berfungsi untuk melakukan pemodelan. Penggunaan UML tidak terbatas pada metodologi tertentu, meskipun UML banyak digunakan pada metodologi berorientasi objek [11].

1) Use Case Diagram: Use case diagram mendeskripsikan sebuah interaksi antara satu atau lebih aktor dengan sistem informasi yang akan dibuat. Dengan kata lain, use case diagram digunakan untuk mengetahui fungsi-fungsi apa saja yang terdapat di dalam sistem dan siapa saja yang berhak mengakses fungsi tersebut [11].

2) Class Diagram: Diagram kelas atau class diagram menggambarkan struktur sistem dari segi pendefinisian kelas-kelas yang akan dibuat untuk membangun sistem. Class diagram memiliki apa yang disebut atribut dan metode atau operasi. Atribut merupakan variabel-variabel 
yang dimiliki oleh suatu kelas. Metode atau operasi adalah fungsi-fungsi yang dimiliki oleh suatu kelas [11].

3) Activity Diagram: Diagram aktivitas atau activity diagram menggambarkan workflow (aliran kerja) atau aktivitas dari sebuah sistem atau proses bisnis. Diagram aktivitas menggambarkan aktivitas sistem bukan apa yang dilakukan aktor, tetapi aktivitas yang dapat dilakukan oleh sistem [11].

4) Sequence Diagram: Diagram sekuen menggambarkan kelakuan objek pada use case dengan mendeskripsikan waktu hidup objek dengan message yang dikirimkan dan diterima antar objek. Menggambarkan diagram sekuen harus diketahui objek-objek yang terlibat dalam sebuah use case beserta metode-metode yang dimiliki kelas yang diinstansiasi menjadi objek itu [11].

\section{H. $M y S Q L$}

Referensi [12] mengatakan bahwa $M y S Q L$ adalah salah satu jenis database server yang banyak digunakan karena menggunakan SQL sebagai bahasa dasar untuk mengakses database sehingga mudah untuk digunakan, kinerja query cepat, dan mencukupi untuk kebutuhan database perusahaan-perusahaan skala menengah kecil. Selain itu, $M y S Q L$ juga bersifat open source dan gratis pada berbagai platform. Pada $M y S Q L$, sebuah database mengandung satu atau sejumlah tabel. Tabel tersebut terdiri atas sejumlah kolom dan baris, dimana setiap kolom berisi sekumpulan data yang memiliki tipe yang sejenis, dan baris yaitu sekumpulan data yang saling berkaitan dan membentuk informasi.

\section{Hypertext Preprocessor (PHP)}

PHP merupakan bahasa scripting server - side, dimana pemrosesan datanya dilakukan pada sisi server. Sederhananya, serverlah yang akan menerjemahkan skrip program, baru kemudian hasilnya akan dikirim kepada client yang melakukan permintaan. Adapun pengertian lain PHP adalah akronim dari Hypertext Preprocessor, yaitu suatu bahasa pemrograman berbasiskan kode - kode (script) yang digunakan untuk mengolah suatu data dan mengirimkannya kembali ke web browser menjadi kode HTML [13].

\section{J. Framework Codeigniter}

Framework adalah rangka atau kerangka, arti istilah tersebut dalam dunia pemrograman adalah kumpulan kelas (class) dan fungsi (function, method) yang disusun secara sistematis berdasarkan kegunaan atau fungsi tertentu untuk mempermudah pembuatan atau pengembangan suatu aplikasi [14].

Codeigniter adalah framework aplikasi web yang open source untuk bahasa pemrograman PHP. Codeigniter memiliki banyak fitur yang membuatnya berbeda dengan framework lainnya. Tidak seperti beberapa framework PHP lainnya, dokumentasi untuk framework ini sangat lengkap, yang mencakup seluruh aspek dalam framework. Codeigniter juga mampu berjalan pada lingkungan shared hosting karena memiliki ukuran yang sangat kecil, namun memiliki kinerja yang sangat luar biasa [15].

\section{K. Model-View-Controller (MVC)}

Model-View-Controller (MVC) adalah pola desain pengembangan perangkat lunak. MVC adalah sebuah pendekatan untuk memisahkan aplikasi menjadi tiga segmen, yaitu Models, Views, dan Controllers. MVC menstruktuisasi aplikasi dengan cara tersebut untuk mempromosikan penggunaan kembali dari kode program [16].

\section{PERANCANGAN SISTEM}

\section{A. Perancangan Arsitektur Sistem}

Aplikasi yang dibangun berbasis web, arsitektur sistem merupakan cara yang digunakan untuk menggambarkan sistem yang berjalan sekarang ini yang didapat dari dinas. Adapun arsitektur sistem yang dapat dilihat pada Gambar 2 .



Gambar. 2 Arsitektur sistem

\section{B. Use Case Diagram}

Berikut merupakan use case diagram dari aplikasi pemilihan staf berprestasi.

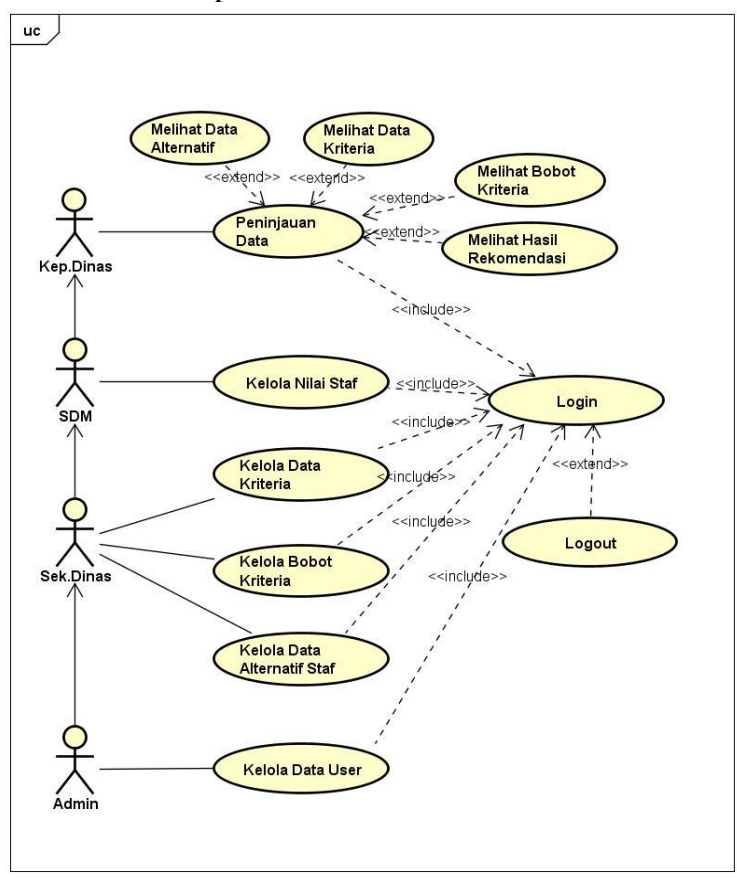

Gambar. 3 Use Case Diagram 


\section{Struktur Antarmuka Sistem}

Antarmuka merupakan tampilan dari suatu program aplikasi yang berperan sebagai sarana interaksi antara aplikasi dengan user/pengguna aplikasi.



Gambar. 4 Struktur Antarmuka Sistem

\section{Hasil Perancangan}

Halaman login adalah halaman pertama yang dijalankan ketika mengakses aplikasi pemilihan staf berprestasi Dinas Pangan Pertanian dan Perikanan Kota Pontianak sebelum mengakses halaman utama. Antarmuka hasil perancangan halaman login dapat dilihat pada Gambar 5.

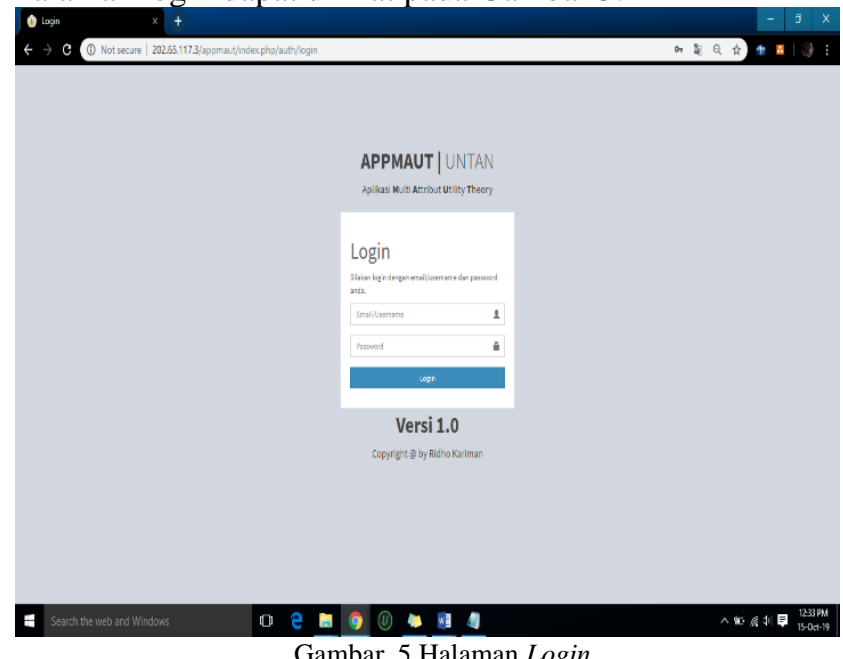

Antarmuka aplikasi pemilihan staf berprestasi ini terdiri dari empat bagian yaitu bagian yang dapat diakses oleh bagian Administrator, bagian-bagian yang dapat diakses oleh Kepala Dinas, Sekretaris Dinas, dan SDM Dinas Pangan Pertanian dan Perikanan.

Antarmuka halaman admin merupakan halaman yang digunakan oleh pengguna untuk mengakses menu-menu yang terdapat pada aplikasi pada Tabel II Pemilihan Staf Berprestasi menggunakan Metode Multi Attribute Utility
Theory (MAUT). Antarmuka hasil perancangan halaman admin dapat dilihat pada Gambar 6



TABEL II

DAFTAR MENU ADMIN DAN FUNGSINYA

\begin{tabular}{|c|c|}
\hline Menu & Fungsi \\
\hline Login & $\begin{array}{l}\text { Proses untuk memulai penggunaan } \\
\text { aplikasi dengan verifikasi kata sandi agar } \\
\text { dapat masuk ke dalam aplikasi. }\end{array}$ \\
\hline Logout & $\begin{array}{l}\text { Proses yang dilakukan untuk mengakhiri } \\
\text { penggunaan aplikasi agar dapat keluar dari } \\
\text { aplikasi. }\end{array}$ \\
\hline $\begin{array}{l}\text { Ubah Data } \\
\text { Admin }\end{array}$ & $\begin{array}{l}\text { Proses untuk mengubah akun admin yang } \\
\text { akan digunakan agar dapat masuk ke } \\
\text { dalam aplikasi. }\end{array}$ \\
\hline $\begin{array}{l}\text { Kelola Data } \\
\text { User }\end{array}$ & $\begin{array}{l}\text { Proses untuk mengelola data user yang } \\
\text { akan digunakan agar dapat masuk ke } \\
\text { dalam aplikasi. }\end{array}$ \\
\hline $\begin{array}{l}\text { Kelola Kriteria } \\
\text { dan Bobot }\end{array}$ & $\begin{array}{l}\text { Proses yang di dalamnya terdapat proses } \\
\text { melihat data kriteria dan bobot, tambah } \\
\text { data kriteria dan bobot, ubah kriteria dan } \\
\text { bobot, dan hapus kriteria dan bobot. }\end{array}$ \\
\hline $\begin{array}{l}\text { Kelola } \\
\text { Alternatif Staf }\end{array}$ & $\begin{array}{l}\text { Proses yang di dalamnya terdapat proses } \\
\text { melihat data alternatif staf, tambah data } \\
\text { alternatif staf, ubah data alternatif, dan } \\
\text { hapus data alternatif. }\end{array}$ \\
\hline $\begin{array}{l}\text { Input } \quad \text { Data } \\
\text { Nilai }\end{array}$ & $\begin{array}{l}\text { Memasukkan data nilai setiap alternatif } \\
\text { staf berdasarkan bobot kriteria untuk } \\
\text { menghitung hasil perhitungan dan } \\
\text { mendapatkan skor. }\end{array}$ \\
\hline $\begin{array}{l}\text { Melihat Hasil } \\
\text { Perangkingan }\end{array}$ & $\begin{array}{l}\text { Proses untuk melihat data } \\
\text { perangkingan dari data } \\
\text { dimasukkan sebelumnya. }\end{array}$ \\
\hline
\end{tabular}




\section{E. Hasil Pengujian}

Berdasarkan Table III, dari skor perhitungan dengan cara manual dan skor perhitungan dengan aplikasi dapat dilihat bahwa aplikasi pemilihan staf berprestasi dengan menggunakan metode MAUT ini dapat menghitung skor dengan hasil yang hampir sama dengan hasil perhitungan secara manual dan urutan perangkingan nama alternatif staf dengan hasil yang sama, perbedaan tersebut didapat karena terjadi pembulatan angka ketika perhitungan data dilakukan.

TABEL III

PERBANDINGAN SKOR ALTERNATIF STAF

\begin{tabular}{|l|c|c|}
\hline \multicolumn{1}{|c|}{ Nama } & \multicolumn{1}{|c|}{$\begin{array}{c}\text { Skor } \\
\text { Perhitungan } \\
\text { Manual }\end{array}$} & $\begin{array}{c}\text { Skor } \\
\text { Perhitungan } \\
\text { Aplikasi }\end{array}$ \\
\hline Devi Tirtaningsih & 3.9968 & 4 \\
\hline Sunarko & 3.9968 & 4 \\
\hline $\begin{array}{l}\text { Apriani } \\
\text { Wijayasuna }\end{array}$ & 3.951 & 3.954170317 \\
\hline Indri Buanti & 3.951 & 3.954170317 \\
\hline Deni & 3.951 & 3.954170317 \\
\hline Edi Setiawan & 3.5442 & 3.546612951 \\
\hline Endang Saputra & 3.4044 & 3.407557366 \\
\hline Rina Febriana & 3.3586 & 3.361727683 \\
\hline Dafin Arifin & 2.812 & 2.815114732 \\
\hline Ernawati & 2.812 & 2.815114732 \\
\hline
\end{tabular}

\section{F. Analisis Hasil Perancangan}

Perincian hasil analisis aplikasi pemilihan staf berprestasi dengan menggunakan metode Multi Attribute Utility Theory (MAUT) pada Dinas Pangan Pertanian dan Perikanan Kota Pontianak adalah sebagai berikut :

1. Metode Multi Attribute Utility Theory (MAUT) digunakan untuk menghitung bobot dari setiap kriteria, serta menghitung skor hasil rekomendasi staf berdasarkan bobot setiap kriteria yang dikalikan dengan nilai setiap kriteria yang dimiliki oleh alternatif staf, dengan kriteria sebanyak 5 macam dan dengan masukkan nilai yang berbeda pula.

2. Pada perhitungan hasil rekomendasi nilai alternatif staf, aplikasi akan memberikan informasi dengan menampilkan skor dari setiap alternatif staf mulai dari nilai tertinggi ke nilai terendah guna membantu dalam pengambilan keputusan memilih staf berprestasi pada Dinas Pangan Pertanian dan Perikanan Kota Pontianak.

3. Setelah dilakukan pengujian akurasi antara perhitungan menggunakan aplikasi dan perhitungan menggunakan cara manual, ternyata perhitungan nilai alternatif staf dengan metode MAUT dilakukan dengan 10 (sepuluh) data alternatif staf Dinas Pangan Pertanian dan Perikanan Kota Pontianak didapatkan hasil yang hampir sama dengan hasil perhitungan secara manual.

\section{KESIMPULAN}

Berdasarkan hasil analisis dan pengujian terhadap aplikasi pemilihan staf berprestasi untuk menghasilkan rekomendasi skor staf dari yang tertinggi ke skor terendah, maka dapat ditarik kesimpulan sebagai berikut Aplikasi pemilihan staf berprestasi berhasil dibangun menggunakan metode Multi Attribute Utility Theory (MAUT) berdasarkan fungsi yang telah dibuat sesuai dengan fungsi yang diperlukan. Aplikasi menerapkan 5 kriteria yang ada seperti tingkat penyelesaian pekerjaan, kehadiran kerja, kehadiran apel pagi, kualitas hasil pekerjaan, dan ketepatan dalam menjalankan tugas berjalan dengan cukup baik sesuai fungsi aplikasi karena dapat menghasilkan rekomendasi staf berprestasi dari skor tertinggi ke skor terendah, dengan perbandingan antara hasil perhitungan aplikasi menggunakan metode MAUT dan hasil perhitungan menggunakan cara manual yang hampir sama.

\section{DAFTAR PUSTAKA}

[1] D. P. P. D. P. KOTA PONTIANAK, PROFIL 2018 DINAS PANGAN PERTANIAN DAN PERIKANAN KOTA PONTIANAK KOTA PONTIANAK: DINAS PANGAN PERTANIAN DAN PERIKANAN, 2018.

[2] S. Rahayu, "Pengaruh Promosi Jabatan terhadap Kinerja Karyawan pada PT. Garuda Metalindo," J. Kreat., vol. 5, no. 1, pp. 18-29, 2017.

[3] A. R. L. Francisco, "ANALISIS MANAJEMEN CONTROL DALAM MENINGKATKAN EFEKTIFITAS KINERJA APARATUR PEMERINTAHAN KAMPUNG TAMBAT KABUPATEN MERAUKE," J. Chem. Inf. Model., vol. 53, no. 9, pp. 1689-1699, 2013.

[4] I. Yelipele, "KINERJA PEGAWAI HONORER PADA DINAS PENDIDIKAN," ji@p, vol. 5, no. 2, pp. 150-186, 2018.

[5] A. F. Nurudin, "Aplikasi Prediksi Hasil Panen Padi Dengan Metode Least Square," Tek. Inform., pp. 1-11, 2015.

[6] Andi Juansyah, "Pembangunan Aplikasi Child Tracker Berbasis Assisted - Global Positioning System ( A-GPS ) Dengan Platform Android," J. Ilm. Komput. dan Inform., vol. 1, no. 1, pp. 1-8, 2015.

[7] M. Ramzi, "Rancang Bangun Aplikasi Penjadwalan Mata Pelajaran Berbasis Web Pada SMK Negeri I Cerme," Perpust. Undika, 2013.

[8] R. Ariefianto and M. A. Irwansyah, Menggunakan Metode Analytical Hierarchy Proscess ( Studi Kasus : Pt. Infomedia Solusi Humanika ( Insani ) Kalimantan Barat ). KOTA PONTIANAK: Program Studi Teknik Informatika Fakultas Teknik Universitas Tanjungpura, 2015.

[9] D. Nofriansyah, S. Kom, M. Kom, and S. T. Dharma, Modul : Sistem Pendukung Keputusan. Medan: STMIK TRIGUNA DHARMA, 2016

[10] R. A. Siswo, SISTEM PENDUKUNG KEPUTUSAN UNTUK PENERIMAAN KARYAWAN PT PLN JEMBER MENGGUNAKAN METODE MULTI ATTRIBUTE UTILITY THEORY (MAUT). Jember: Universitas Muhammadiyah, 2017.

[11] Y. A. Pratama and E. Junianto, "Sistem Pakar Diagnosa Penyakit Ginjal Dan Saluran Kemih Dengan Metode Breadth First Search," J. Inform., vol. 2, no. 1, 2016.

[12] A. Solihin, "Mysq1 5 Dari Pemulah hingga Mahir," Univ. Budi Luhur, Jakarta, 2010.

[13] Anhar, Panduan Menguasai PHP \& MySQL Secara Otodidak, 1st ed. Jakarta: Mediakita, 2010.

[14] Pratama, Codeigniter : Cara Mudah Membangun Aplikasi PHP, 1st ed. Jakarta: Mediakita, 2010.

[15] B. Sidik, "Framework Codeigniter," Bandung Inform., 2012

[16] Griffiths, Codeigniter 1.7 Professional Development. Birmingham: Packt Publishing, 2010. 